\title{
ANALISIS PEMBELAJARAN DAN KUALITAS PELAYANAN TERHADAP KEPUASAN MAHASISWA DAN LOYALITAS MAHASISWA
}

\author{
La Ode Almana* \\ Sudarmanto Saeka* \\ Ismail Suardi Wekke** \\ *Sekolah Tinggi Ilmu Ekonomi Enam Enam, Kendari
**Sekolah Tinggi Agama Islam Negeri (STAIN) Sorong
}

\section{Pendahuluan}

Perkembangan pendidikan khususnya Perguruan Tinggi (PT) yang ada di Indonesia baik yang berstatus negeri maupun swasta dituntut untuk selalu mengambangkan ilmu pengetahuan dan teknologi. Oleh karena itu fungsi perguruan tinggi sangat strategi dalam meningkatkan kualitas sumber daya, baik Sumber daya manusia maupun sarana prasarana pendidikan. Perguruan tinggi dituntut untuk selalu melakukan perubahan menuju perbaikan pendidikan yang lebih maju, mandiri dan berkualitas sesuai dengan tuntutan lingkungan global yang selalu berubah dengan cepat.

Penyelenggaran

pendidikan selayaknya mencermati kualitas pelayanan. Kegiatan pendidikan tidak hanya diorientasikan pada hasil akhir proses pendidikan, melainkan juga melalui pembuktian akuntabilitas yang baik meliputi jaminan kualitas (quality assurance), pengendalian kualitas (quality control), dan perbaikan kualitas (quality improvement) (Badan Akreditasi Nasional Perguruan Tinggi, 1998).

Keberhasilan perguruan tinggi meningkatkan kepuasan mahasiswanya akan dapat mempertahankan jumlah peminat calon mahasiswa baru sehingga perguruan tinggi tersebut akan tetap tumbuh dan berkembang secara berkelanjutan (Zeithaml, 1993). Perguruan tinggi sebagai salah satu organisasi jasa, saat ini mengalami perubahan yang fundamental. Perubahan ini bukan hanya disebabkan karena pesatnya perkembangan ilmu, teknologi dan informasi, melainkan juga karena perubahan ekspektasi masyarakat terhadap peran perguruan tinggi dimasa yang akan datang. Aktivitas tersebut dapat berjalan jika institusi memiliki resources sebagai berikut: (1) mahasiswa (2) reputasi; (3) sarana dan prasarana yang memadai; (4) pembiayaan (funding). Secara teoritis loyalitas pelanggan atau mahasiswa dipengaruhi oleh beberapa faktor antara lain pembelajaran, kualitas layanan dan kepuasan.

Perguruan tinggi perlu menyadari arti pentingnya kualitas layanan pendidikan. Kualitas layanan yang baik mampu meningkatkan kepuasan konsumen (Margareta, 2004). Artinya bahwa kemampuan perguruan tinggi dalam memberikan pelayanan yang cepat dan tepat kepada mahasiswa akan meningkatkan kepuasan mahasiswa terhadap institusi STIE Enam Enam Kendari.

Secara keseluruhan jumlah mahasiswa STIE Enam Enam Kendari mengalami perkembangan yang signifikan dari tahun 2012 sampai dengan 2015. Hal ini mengindikasikan bahwa semakin meninngkatnya persaingan Perguruan tinggi sehingga mengharuskan STIE Enam Enam Kendari melakukan perbaikan dalam hal sistem pembelajaran dan kualitas layanan yang diharapkan dapat memberikan kepuasan dan loyalitas kepada mahaiswa.

Tidak jauh berbeda dari pelayanan publik oleh aparatur pemerintah di lembaga lain, STIE Enam Enam Kendari sebagai salah satu Perguruan Tinggi yang ada di Kota Kendari, masih dijumpai kelemahan. Hal ini ditandai dengan masih adanya 
berbagai keluhan mahasiswa seperti sistem pembelajaran yang tercermin dalam rencana pembelajaran dimana dosen tidak menyediakan SAP dan GBPP sebelum dimulainya perkuliahan, kualitas pembelajaran dosen yang tercermin dalam inkonsistensinya materi yang dibawakan dengan SAP yang telah disiapkan. Selain itu keluhan mahasiswa juga terjadi pada kualitas layanan STIE Enan Enam Kendari seperti Ruang kuliah yang kurang memadai, Performance dosen kurang meyakinkan mahasiswa, Staff kurang profesional dalam memberikan pelayanan kepada mahasiswa.

Berdasarkan fenomena empiris di atas, maka masalah tersebut sangat menarik untuk dikaji lebih lanjut. Oleh karena itu penelitian ini mengambil objek pada STIE Enam Enam Kendari sebagai salah satu perguruan tinggi swasta yang mempunyai tanggungjawab dalam memberikan pelayanan kepada mahasiswa dan dosen secara optimal. STIE Enam Enam harus mampu memberikan konsep pelayanan optimal dengan konsep relationship marketing sehingga dapat meningkatkan kepuasan sebagai upaya mewujudkan loyalitas mahasiswa dan peningkatan kinerja STIE Enam Enam.

\section{Metode Penelitian}

Penelitian ini merupakan penelitian explanatoris yang bertujuan untuk menemukan penjelasan tentang pengaruh fungsional atau hubungan antar variabel dengan variabel lain dan melakukan pengujian hipotesis (Singarimbun dan Effendi, 1995).

Pada penelitian ini yang menjadi populasi adalah mahasiswa yang menggunakan jasa STIE Enam Enam Kendari mulai tahun akademik 2010/2011 sampai dengan tahun akademik 2014/2015 yang berjumlah 1114 mahasiswa. Dimana besarnya sampel disesuaikan dengan alat analisis yang digunakan yaitu analisis Structural Equation Model (SEM).

Peneltian ini terdiri dari empat variabel dan 15 Indikator maka jumlah sampel dalam penelitian ini adalah 8 kali jumlah parameter yang diestimasi atau indikator yang digunakan, dengan demikian jumlah sampel dalam penelitian ini adalah 120 responden.

\section{A. Teknik Pengumpulan Data}

Dalam melakukan penelitian ini peneliti melakukan teknik pengumpulan data sebagai berikut:

1) Kuesioner yang didistribusikan kepada mahasiswa STIE Enam Enam Kendari yang menjadi responden dalam penelitian, untuk mengetahui tanggapan responden mengenai Proses Pembelajaran dan Kualitas Pelayanan, Responden akan diminta untuk memberi jawaban yang berupa kuesioner dalam bentuk skala 1-5 dengan kategori jawaban sangat tidak setuju (STS) sampai dengan sangat setuju (SS).

2) Studi dokumentasi, yaitu mengumpulkan dan mempelajari data atau dokumen yang mendukung penelitian.

\section{B. Sumber Data}

Sumber data yang dikumpulkan dalam penelitian ini adalah:

1) Data Primer adalah data yang diperoleh dengan melakukan penyebaran daftar pertanyaan (questioner) kepada responden penelitian.

2) Data sekunder adalah data yang berasal dari dokumen-dokumen penunjang yang mendukung penelitian ini seperti profil STIE Enam Enam Kendari, struktur Organisasi, data dibagian akademik.

\section{Uji Validitas dan Uji Realiabilitas}

1) Uji Validitas

Dalam pengujian validitas, instrumen diuji dengan menghitung koefisien korelasi antara skor item dan skor totalnya dalam taraf signifikansi $95 \%$ atau $\alpha=0,05$. Instrumen dikatakan valid mempunyai nilai signifikansi korelasi $\leq$ dari $95 \%$ atau $\alpha=0,05$. (Santoso, 2002). Uji validitas dilakukan dengan menggunakan koefisien korelasi product moment kriteria pengujian yang digunakan pada instrumen yang dikatakan valid jika nilai $\mathrm{r} \geq 0,30$ (cut of point) Sugiyono, (2010). Untuk mengukur validitas digunakan rumus Pearson Product Moment dengan rumus sebagai berikut :

$\mathrm{r}_{\text {hitung }}=\frac{n \sum X i Y i-\left(\sum X i\right)\left(\sum Y i\right)}{\sqrt{\left[N \sum X i x^{2}-\left(\sum X i\right) x^{2}\right]\left[n \sum Y i x^{2}-\left(\sum Y i\right) x^{2}\right]}}$ 
Keterangan :

$\mathrm{r}_{\text {hitung }}=$ koefisien korelasi

$\mathrm{n} \quad=$ jumlah responden

$\sum X i=$ jumlah skor item

$\sum Y i=$ jumlah skor total (dari seluruh item)

Jika instrumen itu valid, maka dilihat kriteria penafsiran mengenai indeks korelasinya $\left(\mathrm{r}_{\text {hitung }}\right.$ ) apabila nilai korelasi > 0,50 maka instrument tersebut valid. Selanjutnya dihitung dengan uji t dengan rumus :

$\mathrm{t}_{\text {hitung }}=\frac{\sqrt{n-2}}{\sqrt{1-r}}$

Keterangan :

$\mathrm{t}=$ nilai $\mathrm{t}_{\text {hitung }}$

$\mathrm{r}=$ koefisien korelasi hasil $\mathrm{r}_{\text {hitung }}$

Kaidah keputusan :

jika $t_{\text {hitung }}>\mathrm{t}_{\text {tabel }}=$ valid

Jika $\mathrm{t}_{\text {hitung }}<\mathrm{t}_{\text {tabel }}=$ tidak valid

2) Uji Reabilitas

Untuk menguji tingkat reliabilitas instrumen dalam penelitian ini dilakukan melalui uji internal Concistency dengan menggunakan koefisien reliabilitas (Alpha Cronbach).

\section{Teknik Analisis Data}

Dalam penelitian ini, analisis data dilakukan dua tahapan, yaitu:

1) Deskriptif variabel

Nilai rata-rata pembobotan atau nilai skor jawaban responden yang diperoleh diklasifikasi kedalam rentang skala kategori nilai yang disajikan pada Tabel 1 .

Tabel 1. Penentuan kategori rata-rata skor penyataan responden dan makna penilaian secara deskriptif

\begin{tabular}{ccc}
\hline No & $\begin{array}{c}\text { Nilai Rata-rata } \\
\text { skor jawaban }\end{array}$ & Makna/interpretasi \\
\hline 1 & $1,00-1,80$ & Sangat Rendah \\
2 & $1,81-2,61$ & Rendah \\
3 & $2,62-3,40$ & Cukup tinggi \\
4 & $3,41-4,21$ & Tinggi \\
5 & $4,22-5,00$ & Sangat tinggi \\
\hline
\end{tabular}

Sumber : Sugiyono 2005

2) Analisis Structural Equation Modeling (SEM)

Structural Equation Modeling (SEM) dengan menggunakan pengolahan program AMOS ( Analysis Of Moment Structural).
Penerapan tehnik analisis SEM digunakan dalam studi meliputi beberapa tahapan yaitu: Pertama : Uji Asumsi SEM. Uji asumsi digunakan untuk mengetahui data yang diperoleh dari hasil pengamatan memenuhi syarat persamaan struktural atau tidak. Uji asumsi SEM yang digunakan dalam penelitian ini, antara lain:

\section{a. Uji normalitas dan uji outlier.}

Uji normalitas data menggunakan metode univariate normality dengan melihat koefisien indeks skew univariate(kecondongan) dan indeks kurtosis univariate (tinggi-datar). Data memenuhi syarat normalitas data jika koefisien indeks skew univariate dan indeks kurtosis univariate berada diantara 0 sampai $\pm 2,58$ (Ferdinand, 2005:139).

\section{b. Uji outlier}

Pengujian outliers dalam penelitian ini menggunakan kriteria Jarak Mahalanobis (Mahalanobis distance pada tingkat probabilitas lebih kecil dari 0,001= $\mathrm{p}<0,001)$. Jarak Mahalanobis dievaluasi dengan menggunakan $\chi^{2}$ pada derajat bebas sebesar jumlah variabel (observed variable) yang digunakan dalam penelitian itu. Jika nilai mahalanobis distance $>$ nilai $\chi^{2}$ maka terdapat outlier, begitu pula sebaliknya. Nilai $\chi^{2}$ diperoleh dengan bantuan software Microsoft Excel dengan menggunakan jumlah indicator dan nilai level of significance yang ditetapkan.

\section{c. Uji linearitas}

Pengujian linearitas dalam penelitian ini menggunakan curva fit. Hasil analisis menunjukkan bahwa model linear yang dihasilkan signifikan $(0,000)$.

Kedua : Pengukuran validitas dan reliabilitas indikator dalam membentuk konstruk penanganan komplain, kepuasan, kepercayaan, terhadap komitmen dan loyalitas nasabah. Indikator dikatakan valid mengukur konstruknya jika koefisien korelasi antar iten-total skor indikator (r) > 0,60. Konstruk dianggap reliabel jika koefisien alpha Cronbach > 0,70.

Ketiga : Analisis kesesuaian model digunakan untuk mengetahui derajad kesesuaian model yang diestimasi dengan 
data hasil observasi. Kriteria yang digunakan seperti Tabel 2.

Tabel 2. Kriteria Kesesuaian Model Fit

\begin{tabular}{|c|c|c|c|}
\hline Goodness of fit & Cutt-off & Keterangan & Sumber \\
\hline Khi-Kuadrat & Kecil & Digunakan untuk $n=100-200$ & Solimun ,2004 \\
\hline Probability & Non signifikan & Dibandingkan dengan signifikan & Solimun, 2004 \\
\hline GFI & $\geq 0,90$ & $\begin{array}{l}\text { Membandigkan poor fit dengan } \\
\text { perfect fit }\end{array}$ & Solimun, 2004 \\
\hline AGFI & $\geq 0,90$ & Tingkat penerimaan yang lebih tinggi & Solimun, 2004 \\
\hline$T L I$ & $\geq 0,90$ & $\begin{array}{l}\text { Membandingkan proposed model } \\
\text { dengan null model }\end{array}$ & Ghozali,2004:20 \\
\hline CFI & $\geq 0,90$ & Tidak sensitif terhadap besar sampel & Ghozali,2004:20 \\
\hline RMSEA & $\geq 0,05-0,08$ & Digunakan untuk $\mathrm{n}$ besar & Solimun, 2004 \\
\hline \multicolumn{4}{|c|}{ Keterangan : } \\
\hline \multicolumn{4}{|c|}{$\begin{array}{l}=\text { Good Of Fit Index } \\
=\text { Adjusted Of Fit Indeks }\end{array}$} \\
\hline \multirow{2}{*}{\multicolumn{4}{|c|}{$\begin{array}{l}=\text { The Root Mean Square Er } \\
=\text { Comparative Fit Index }\end{array}$}} \\
\hline \multicolumn{2}{|c|}{$\begin{array}{l}=\text { Comparative Fit Index } \\
=\text { Normed Fit Index }\end{array}$} & & \\
\hline \multicolumn{4}{|c|}{$\begin{array}{l}=\text { Normed Fit Index } \\
=\text { Turker Levis Index }\end{array}$} \\
\hline
\end{tabular}

Model yang dibangun dalam penelitian ini dikatakan sesuai dengan data hasil observasi jika nilai khi-kuadrat tidak signifikan, RMSEA $\leq 0,08, C F I \geq 0,90$, $T L I \geq 0,90$, GFI $\geq 0,90$, dan AGFI $\geq 0,90$. Jika model yang dibangun belum layak diterima, maka langkah selanjutnya melakukan modifikasi model untuk mendapatkan model yang fit.

Keempat adalah Analisis pengaruh struktural. Analisis ini dilakukan untuk mengetahui hubungan struktural antara variabel laten dan hubungan struktural indikatornya dengan melihat koefisien standardized regression weigth dan factor loading.

Kelima : Pengujian hipotesis dengan membandingkan nilai $\mathrm{t}$ hitung dengan nilai $\mathrm{t}$ Tabel. Jika nilai $\mathrm{t}$ hitung lebih besar dibanding nilai $\mathrm{t}$ Tabel, maka hipotesis diterima sebaliknya jika nilai $\mathrm{t}$ hitung lebih kecil dari nilai $\mathrm{t}$ Tabel, maka hipotesis ditolak. Pengujian hipotesis juga bisa didasarkan pada nilai probability, jika $\mathrm{p}<0,05$ maka $\mathrm{H}_{\mathrm{A}}$ diterima dan $\mathrm{H}_{0}$ ditolak.

Keenam : Melakukan interprestasi hasil pengujian hipotesis dikaitkan dengan teori dan hasil-hasil penelitian terdahulu.

\section{Hasil Pengamatan}

\section{A. Deskripsi Variabel Pembelajaran (P)}

Hasil deskripsi jawaban responden terhadap variabel kepuasan pada indikator variabel dan item pernyataan responden, disajikan pada Tabel 3.

Tabel 3.Deskripsi Variabel Pembelajaran (P)

\begin{tabular}{|c|c|c|c|c|c|c|c|c|c|c|c|c|c|}
\hline \multirow{3}{*}{$\begin{array}{l}\text { Indikator } \\
\text { Variabel }\end{array}$} & \multirow{3}{*}{$\begin{array}{l}\text { Item } \\
\text { (Butir) }\end{array}$} & \multicolumn{10}{|c|}{ Frekwensi (f) dan Persentase (\%) } & \multirow{2}{*}{\multicolumn{2}{|c|}{$\begin{array}{l}\text { Rerata } \\
\text { (Mean) }\end{array}$}} \\
\hline & & \multicolumn{2}{|c|}{ STS (1) } & \multicolumn{2}{|c|}{ TS (2) } & \multicolumn{2}{|c|}{$\mathbf{N}(3)$} & \multicolumn{2}{|c|}{$S(4)$} & \multicolumn{2}{|c|}{ SS (5) } & & \\
\hline & & $\mathbf{F}$ & $\%$ & f & $\%$ & f & $\%$ & f & $\%$ & $\mathbf{F}$ & $\%$ & Item & $\begin{array}{c}\text { Indi } \\
\text { kato } \\
\mathbf{r}\end{array}$ \\
\hline \multirow{4}{*}{$\begin{array}{c}\text { Rencana } \\
\text { Pembelajar } \\
\text { an } \\
(\mathrm{P} 1) \\
\end{array}$} & $\left(\mathrm{P}_{1.1}\right)$ & 2 & 1,7 & 21 & 17,5 & 21 & 17,5 & 53 & 44,2 & 23 & 19,2 & 3,62 & \multirow[b]{2}{*}{3,59} \\
\hline & $\left(\mathrm{P}_{1.2}\right)$ & 3 & 2,5 & 20 & 16,7 & 25 & 20,8 & 51 & 42,5 & 21 & 17,5 & 3,56 & \\
\hline & & 3 & 2,08 & 21 & 17,1 & 23 & 19,17 & 52 & 43,33 & 22 & 18,33 & 3,59 & \\
\hline & & & & 23 & 19,2 & 23 & 19,17 & & & 74 & 61,67 & 120 & \\
\hline Kualitas & $\left(\mathrm{P}_{2.1}\right)$ & 3 & 2,5 & 20 & 16,7 & 26 & 21,7 & 44 & 36,7 & 27 & 22,5 & 3,60 & 3,51 \\
\hline
\end{tabular}




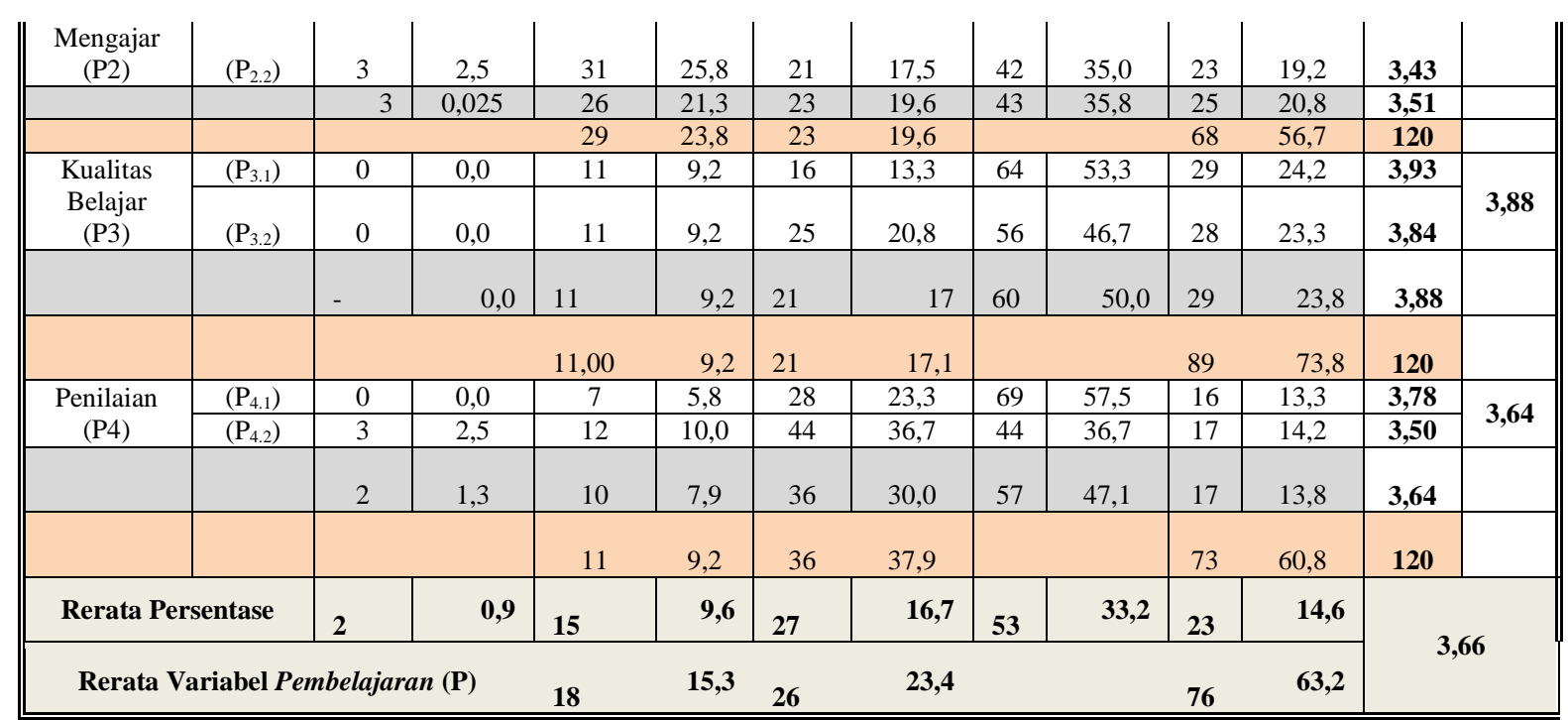

Sumber: Data primer diolah, Tahun 2016

Deskripsi jawaban responden yang disajikan pada Tabel 3. diketahui nilai rerata (mean) variabel pembelajaran $(\mathrm{P})$ sebesar 3,66 yang dapat diartikan sebagian besar mahasiswa di STIE Enam Enam Kendari menyatakan cukup puas terhadap dosen dalam memberikan pembelajaran terhadap mahasiswanya jika dicerminkan dari aspek rencana pembelajaran $\left(\mathrm{P}_{1}\right)$, kualitas mengajar $\left(\mathrm{P}_{2}\right)$, kualitas belajar $\left(\mathrm{P}_{3}\right)$ dan penilaian $\left(\mathrm{P}_{4}\right)$. Tanggapan responden menunjukkan bahwa indikator kualitas belajar memiliki skor rata-rata tertinggi sebesar 3,88 diikuti penilaian sebesar 3,64, rencana pembelajaran sebesar 3,59 dan yang terkecil indikator kualitas mengajar sebesar 3,51.

Hasil analisa keseluruhan deskripsi mahasiswa berdasarkan nilai mean persentase jawaban responden variabel pembelajaran yang menyatakan puas atas layanan pembelajaran masing-masing sebanyak 76 orang $(63,24 \%)$ mahasiswa yang menyatakan tidak puas sebanyak 18 orang $(15,35 \%)$, tetapi disisi lain mahasiswa yang memberikan penilaian cukup puas atas pembelajaran masih tinggi sebanyak 26 orang $(23,44 \%)$ hal ini dapat dimaknai bahwa harapan mahasiswa untuk mencapai pembelajaran yang tinggi tidak terwujud karena tingginya persentase jawaban responden yang memberikan jawaban pada angka 3 (cukup puas).

\section{B. Deskripsi Variabel Kualitas Layanan} (KL)

Kualitas Layanan didefinisikan sebagai persepsi mahasiswa terhadap Tangibles (bukti terukur), Reliability (keandalan), Responsiveness (daya tanggap), Assurance (Jaminan), dan Empathy (empati).

Hasil deskripsi jawaban responden terhadap variabel kualitas layanan mahasiswa pada setiap indikator dan item pernyataan responden, disajikan pada Tabel 4.

Tabel 4. Deskripsi Variabel Kualitas Layanan (KL)

\begin{tabular}{|c|c|c|c|c|c|c|c|c|c|c|c|c|c|}
\hline \multirow{3}{*}{$\begin{array}{l}\text { Indikator } \\
\text { Variabel }\end{array}$} & \multirow{3}{*}{$\begin{array}{l}\text { Item } \\
\text { (Butir) }\end{array}$} & \multicolumn{10}{|c|}{ Frekwensi (f) dan Persentase (\%) } & \multirow{2}{*}{\multicolumn{2}{|c|}{ Rerata (Mean) }} \\
\hline & & \multicolumn{2}{|c|}{ STS (1) } & \multicolumn{2}{|c|}{ TS (2) } & \multicolumn{2}{|c|}{$\mathbf{N}(3)$} & \multicolumn{2}{|c|}{ S (4) } & \multicolumn{2}{|c|}{ SS (5) } & & \\
\hline & & f & $\%$ & f & $\%$ & $\mathbf{f}$ & $\%$ & $\mathbf{f}$ & $\%$ & f & $\%$ & Item & $\begin{array}{c}\text { Indika } \\
\text { tor }\end{array}$ \\
\hline \multirow{5}{*}{$\begin{array}{c}\text { Tengibles } \\
\text { (KL1) }\end{array}$} & $\left(\mathrm{KL}_{1.1}\right)$ & 1 & 0,8 & 14 & 11,7 & 18 & 15,0 & 40 & 33,3 & 47 & 39,2 & 3,98 & \multirow{3}{*}{4,01} \\
\hline & $\left(\mathrm{KL}_{1.2}\right)$ & - & 0,0 & 8 & 6,7 & 26 & 21,7 & 43 & 35,8 & 43 & 35,8 & 4,01 & \\
\hline & $\left(\mathrm{KL}_{1.3}\right)$ & - & 0,0 & 4 & 3,3 & 19 & 15,8 & 67 & 55,8 & 30 & 25,0 & 4,03 & \\
\hline & & 0 & 0,3 & 9 & 7 & 21 & 17,5 & 50 & 41,7 & 40 & 33,3 & 4,01 & \\
\hline & & & & 9 & 8 & 21 & 18 & & & 90 & 75 & 120 & \\
\hline Reliability & $\left(\mathrm{KL}_{2.1}\right)$ & 0 & 0,0 & 5 & 4,2 & 29 & 24,2 & 60 & 50,0 & 26 & 21,7 & $\mathbf{3 , 8 9}$ & 3,96 \\
\hline
\end{tabular}




\begin{tabular}{|c|c|c|c|c|c|c|c|c|c|c|c|c|c|}
\hline$(\mathbf{K L 2})$ & $\left(\mathrm{KL}_{2.2}\right)$ & 0 & 0,0 & 6 & 5,0 & 17 & 14,2 & 65 & 54,2 & 32 & 26,7 & 4,03 & \\
\hline & & - & 0,0 & 6 & 5 & 23 & 19,2 & 63 & 52,1 & 29 & 24,2 & 3,96 & \\
\hline & & & & 6 & 5 & 23 & 19 & & & 92 & 76 & 120 & \\
\hline \multirow{4}{*}{$\begin{array}{c}\text { Responsiveness } \\
\text { (KL3) }\end{array}$} & $\left(\mathrm{KL}_{3.1}\right)$ & 0 & 0,0 & 6 & 5,0 & 24 & 20,0 & 58 & 48,3 & 32 & 26,7 & 3,97 & \multirow[b]{2}{*}{3,99} \\
\hline & $\left(\mathrm{KL}_{3.2}\right)$ & 0 & 0,0 & 7 & 5,8 & 19 & 15,8 & 59 & 49,2 & 35 & 29,2 & 4,02 & \\
\hline & & - & 0,0 & 7 & 5 & 22 & 17,9 & 59 & 48,8 & $\begin{array}{c}33, \\
5\end{array}$ & 27,9 & 3,99 & \\
\hline & & & & 7 & 5 & 22 & 18 & & & 92 & 77 & 120 & \\
\hline \multirow{3}{*}{$\begin{array}{l}\text { Assurance } \\
\text { (KL4) }\end{array}$} & $\left(\mathrm{KL}_{4.1}\right)$ & 1 & 0,8 & 4 & 3,3 & 17 & 14,2 & 54 & 45,0 & 44 & 36,7 & 4,13 & \multirow{3}{*}{3,97} \\
\hline & $\left(\mathrm{KL}_{4.2}\right)$ & 0 & 0,0 & 8 & 6,7 & 18 & 15,0 & 63 & 52,5 & 31 & 25,8 & \begin{tabular}{|l|}
3,98 \\
\end{tabular} & \\
\hline & $\left(\mathrm{KL}_{4.3}\right)$ & 1 & 0,8 & 12 & 10,0 & 20 & 16,7 & 63 & 52,5 & 24 & 20,0 & 3,81 & \\
\hline & & 1 & 0,6 & 8 & 6,7 & 18 & 15,3 & 60 & 50,0 & 33 & 27,5 & 3,97 & \\
\hline & & & & 9 & 7,2 & 18 & 15,3 & & & 93 & 77,5 & 120 & \\
\hline \multirow{2}{*}{$\begin{array}{c}\begin{array}{c}\text { Empathy } \\
\text { (KL5) }\end{array} \\
\end{array}$} & $\left(\mathrm{KL}_{4.1}\right)$ & 2 & 1,7 & 11 & 9,2 & 27 & 22,5 & 58 & 48,3 & 22 & 18,3 & 3,73 & \multirow{2}{*}{3,69} \\
\hline & $\left(\mathrm{KL}_{4.2}\right)$ & 1 & 0,8 & 15 & 12,5 & 33 & 27,5 & 47 & 39,2 & 24 & 20,0 & 3,65 & \\
\hline & & 2 & 1,3 & 13 & 10,8 & 30 & 25,0 & 53 & 43,8 & 23 & 19,2 & 3,69 & \\
\hline & & & & 15 & 12,1 & 30 & 25,0 & & & 76 & 62,9 & 120 & \\
\hline \multicolumn{2}{|c|}{ Rerata Persentase } & 0 & $0,4 \%$ & 8 & $6,9 \%$ & 23 & $19,0 \%$ & 58 & $48,1 \%$ & 34 & $22,6 \%$ & \multirow{2}{*}{\multicolumn{2}{|c|}{3,92}} \\
\hline \multicolumn{4}{|c|}{ Rerata Variabel Kualitas Layanan (KL) } & 9 & $\mathbf{7 , 3 \%}$ & 23 & $18,9 \%$ & & & 88 & $73,6 \%$ & & \\
\hline
\end{tabular}

Sumber: Data primer diolah, Tahun 2016

Berdasarkan Tabel 4. deskripsi responden rerata variabel kualitas layanan mahasiswa menunjukkan nilai keseluruhan sebesar 3,92 sedangkan berdasarkan hasil penilaian mahasiswa menunjukkan bahwa kualitas layanan terbesar mahasiswa pada STIE Enam Enam adalah fasilitas ruang kuliah sangat memadai, sarana pembelajaran ruang kelas sangat memadai dan performance dosen dapat meyakinkan mahasiswa (tangible) sebesar 4,01, diikuti oleh responsif (responsiveness) 3,99, jaminan (assurance) sebesar 3,97, kemudian keandalan (reliability) sebesar 3,96 dan yang paling rendah adalah empati (empaty) sebesar 3,69 yang menunjukan

bahwa staf kurang peduli dan perhatian secara personal kepada mahasiswa.

Berdasarkan penilaian responden secara keseluruhan dapat disimpulkan bahwa mayoritas layanan akademik mahasiswa STIE Enam Enam Kendari secara totalitas sudah baik.

\section{Deskripsi Variabel Kepuasan $(\mathbf{K})$}

Kepuasan merupakan persepsi mahasiswa terhadap emosi, biaya, kualitas pelayanan serta faktor pribadi yang berpengaruh terhadap peningkatan loyalitas mahasiswa.

Hasil jawaban responden terhadap variabel kepuasan mahasiswa pada setiap indikator variabel dan pernyataan responden, disajikan pada Tabel 5.

Tabel 5. Deskripsi Variabel Kepuasan (K)

\begin{tabular}{|c|c|c|c|c|c|c|c|c|c|c|c|c|c|}
\hline \multirow{3}{*}{$\begin{array}{l}\text { Indikator } \\
\text { Variabel }\end{array}$} & \multirow{3}{*}{$\begin{array}{l}\text { Item } \\
\text { (Butir) }\end{array}$} & \multicolumn{10}{|c|}{ Frekwensi (f) dan Persentase (\%) } & \multirow{2}{*}{\multicolumn{2}{|c|}{$\begin{array}{l}\text { Rerata } \\
\text { (Mean) }\end{array}$}} \\
\hline & & \multicolumn{2}{|c|}{ STS (1) } & \multicolumn{2}{|c|}{ TS (2) } & \multicolumn{2}{|c|}{$\mathbf{N}(3)$} & \multicolumn{2}{|c|}{ S (4) } & \multicolumn{2}{|c|}{ SS (5) } & & \\
\hline & & $\mathbf{f}$ & $\%$ & f & $\%$ & f & $\%$ & f & $\%$ & f & $\%$ & Item & $\begin{array}{l}\text { Indi } \\
\text { kato } \\
\mathbf{r}\end{array}$ \\
\hline \multirow{4}{*}{ Emosi (K1) } & $\left(\mathrm{K}_{1.1}\right)$ & 1 & 0,3 & 3 & 0,8 & 3 & 0,8 & 32 & 8,0 & 81 & 20,3 & $\mathbf{4 , 5 8}$ & \multirow{2}{*}{4,54} \\
\hline & $\left(\mathrm{K}_{1.2}\right)$ & 1 & 0,3 & 3 & 0,8 & 4 & 1,0 & 38 & 9,5 & 74 & 18,5 & 4,51 & \\
\hline & & 1 & 0,3 & 3 & 0,8 & 4 & 0,9 & 35 & 8,8 & 78 & 19,4 & 4,54 & \\
\hline & & & & 4 & 1,0 & 4 & 0,9 & & & 113 & 28,1 & 120 & \\
\hline \multirow{4}{*}{ Biaya (K2) } & $\left(\mathrm{K}_{2,1}\right)$ & 3 & 0,8 & 8 & 2,0 & 31 & 7,8 & 52 & 13,0 & 26 & 6,5 & $\mathbf{3 , 7 5}$ & \multirow{3}{*}{3,64} \\
\hline & $\left(\mathrm{K}_{2.2}\right)$ & 5 & 1,3 & 17 & 4,3 & 34 & 8,5 & 46 & 11,5 & 18 & 4,5 & 3,46 & \\
\hline & $(\mathrm{K} 3.2)$ & 2 & 0,5 & 12 & 3,0 & 30 & 7,5 & 49 & 12,3 & 27 & 6,8 & $3, \mathbf{7 3}$ & \\
\hline & & 3,33 & 0,8 & 12,33 & 3,1 & 31,67 & 7,9 & 49 & 12,3 & 23,67 & 5,9 & 3,64 & \\
\hline
\end{tabular}




\begin{tabular}{|c|c|c|c|c|c|c|c|c|c|c|c|c|c|}
\hline & & & & 16 & 3,9 & 32 & 7,9 & & & 73 & 18,2 & 120 & \\
\hline \multirow{4}{*}{$\begin{array}{c}\text { Kualitas } \\
\text { Pelayanan } \\
(\text { K3) }\end{array}$} & $(\mathrm{K} 3.1)$ & 0 & 0,0 & 9 & 2,3 & 26 & 6,5 & 54 & 13,5 & 31 & 7,8 & $\mathbf{3 , 8 9}$ & \multirow{2}{*}{3,89} \\
\hline & $(\mathrm{K} 3.2)$ & 0 & 0,0 & 14 & 3,5 & 18 & 4,5 & 55 & 13,8 & 33 & 8,3 & $\mathbf{3 , 8 9}$ & \\
\hline & & 0 & 0,0 & 11,5 & 2,9 & 22 & 5,5 & 54,5 & 13,6 & 32 & 8,0 & 3,89 & \\
\hline & & & & 11,5 & 2,9 & 22 & 5,5 & & & 86,5 & 21,6 & 120 & \\
\hline \multirow{4}{*}{$\begin{array}{c}\text { Faktor } \\
\text { Pribadi (K4) }\end{array}$} & $(\mathrm{K} 4.1)$ & 1 & 0,3 & 7 & 1,8 & 4 & 1,0 & 43 & 10,8 & 65 & 16,3 & 4,37 & \multirow{2}{*}{3,13} \\
\hline & $(\mathrm{K} 4.2)$ & 48 & 12,0 & 41 & 10,3 & 28 & 7,0 & 3 & 0,8 & 0 & 0,0 & 1,88 & \\
\hline & & 24,5 & 6,1 & 24 & 6,0 & 16 & 4,0 & 23 & 5,8 & 32,5 & 8,1 & 3,13 & \\
\hline & & & & 49 & 12,1 & 16 & 4,0 & & & 56 & 13,9 & 120 & \\
\hline \multicolumn{2}{|c|}{ Rerata Persentase } & 7 & 1,6 & 13 & 3,4 & 18 & 4,6 & 40 & 7,0 & 41 & 13,4 & \multirow{2}{*}{\multicolumn{2}{|c|}{3,80}} \\
\hline \multicolumn{4}{|c|}{ Rerata Variabel Kepuasan (K) } & 20 & 4,9 & 18 & \multicolumn{3}{|l|}{4,5} & 82 & 20,4 & & \\
\hline
\end{tabular}

Sumber: Data primer diolah, Tahun 2016

Berdasarkan Tabel 5. deskripsi responden rerata variabel kepuasan mahasiswa menunjukkan nilai keseluruhan sebesar 3,80. Sedangkan penilaian responden secara keseluruhan dapat disimpulkan bahwa mayoritas kepuasan mahasiswa STIE Enam Enam Kendari secara totalitas sudah baik

\section{Deskripsi Variabel Loyalitas Mahasiswa (L)}

Hasil deskripsi jawaban responden terhadap variabel loyalitas pada setiap indikator variabel dan item pernyataan responden, disajikan pada Tabel 6.

Tabel 6. Deskripsi Variabel Loyalitas Mahasiswa (L)

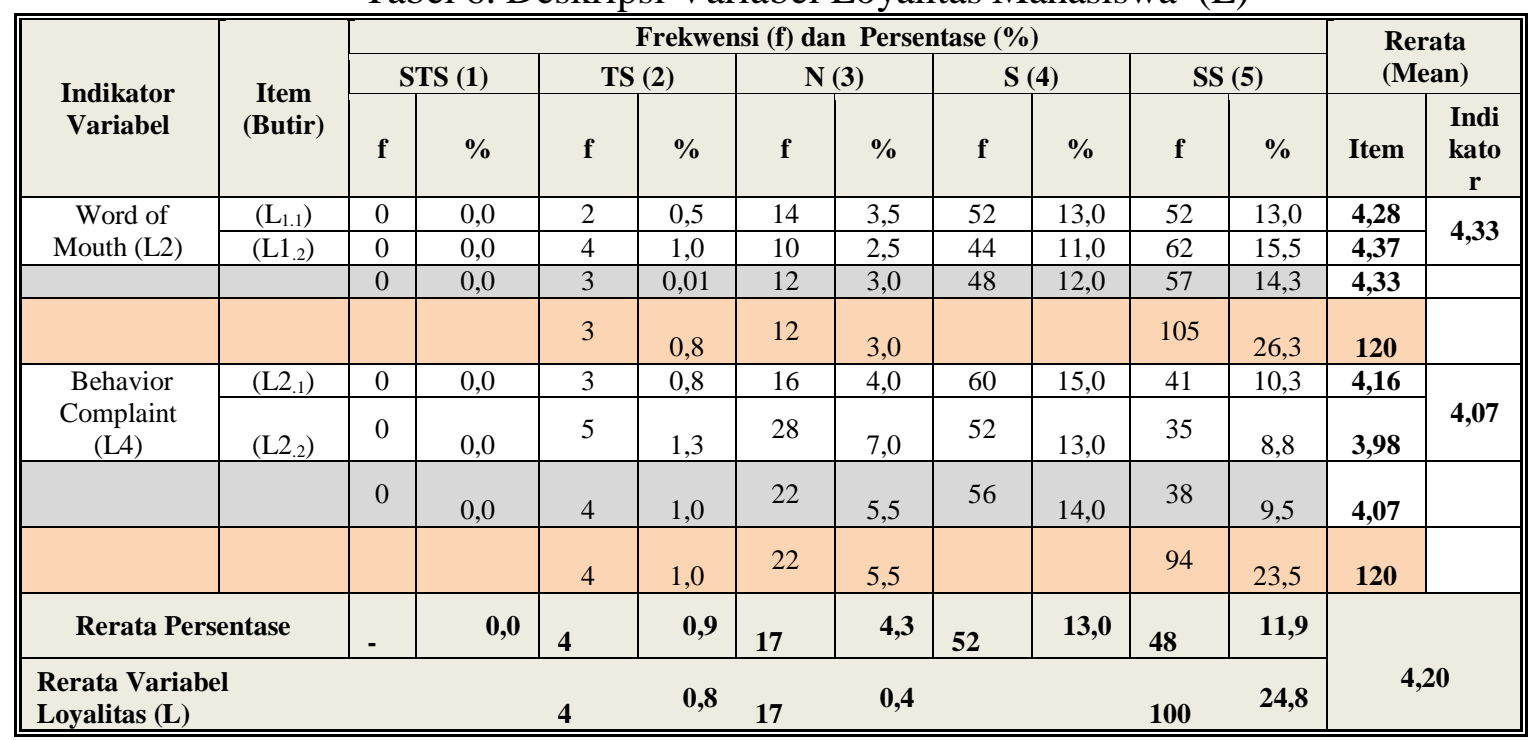

Sumber: Data primer diolah, Tahun 2016

Berdasarkan Tabel 6. deskripsi responden menunjukkan nilai rerata (mean) jawaban responden diperoleh total keseluruhan untuk variabel loyalitas dengan nilai sebesar 4,20. Artinya sebagian besar responden telah loyal terhadap STIE Enam Enam Kendari.

Berdasarkan penilaian responden dapat disimpulkan bahwa loyalitas mahasiswa STIE Enam Enam Kendari secara totalitas sudah baik. Berdasarkan Tabel 6. Mencerminkan bahwa mahasiswa yang menyatakan loyal terhadap STIE Enam Enam sebesar 100 orang $(24,8 \%)$ dan yang menyatakan cukup loyal sebanyak 17 orang $(0,4 \%)$ sedangkan sebanyak 4 orang $(0,8)$ menyatakan tidak loyal terhadap STIE Enam Enam.

\section{E. Uji Analisis Faktor Konfirmatori - CFA}


1) Hasil Estimasi Loading Faktor Variabel Pembelajaran (X)

Model pengukuran confirmatory factor untuk masing-masing observed variabel pembelajaran disajikan pada Tabel berikut:

Tabel 7. Pengukuran confirmatory factor (loding faktor) pembelajaran

\begin{tabular}{lcc}
\hline Indikator & $\begin{array}{c}\text { Standardize } \\
\text { Factor Loading }\end{array}$ & Keterangan \\
\hline$(\mathrm{X} 1.1)$ & 0,91 & \\
$(\mathrm{X} 1.2)$ & 0,94 & Paling Besar \\
$(\mathrm{X} 1.3)$ & 0,67 & \\
$(\mathrm{X} 1.4)$ & 0,72 & \\
\hline
\end{tabular}

Sumber ; Data Primer di Olah 2016

Hasil analisis menunjukkan nilai standardized loading faktor yang diperoleh mengkonfirmasikan bahwa keempat indikator variabel yang memiliki peranan penting atau kontribusi terbesar dalam menjelaskan variabel laten pembelajaran adalah variabel manifest kualitas mengajar dosen dengan nilai loading factor sebesar 0,94. Selanjutnya variabel manifes rencana pembelajaran diperoleh nilai standardized loading factor sebesar 0,91. Menyusul variabel manifes penilaian dan pembelajaran diperoleh nilai standardized loading factor sebesar 0,72.

2) Hasil Estimasi Loading Faktor Variabel Kualitas Layanan (X2)

Model pengukuran confirmatory factor untuk masing-masing observed variabel kualitas layanan disajikan pada Tabel berikut:

Tabel 8. Pengukuran confirmatory factor (loding faktor) variabel kualitas layanan

\begin{tabular}{lcl}
\hline Indikator & $\begin{array}{c}\text { Standardize Factor } \\
\text { Loading }\end{array}$ & Keterangan \\
\hline (X2.1) & 0,58 & \\
$(\mathrm{X} 2.2)$ & 0,76 & \\
$(\mathrm{X} 2.3)$ & 0,82 & Paling Besar \\
$(\mathrm{X} 2.4)$ & 0,87 & \\
(X2.5) & 0,72 & \\
\hline
\end{tabular}

Sumber ; Data Primer di Olah 2016

Berdasarkan pada Tabel 8. menunjukkan hasil estimasi model pengukuran variabel dengan menggunakan standardized loading faktor kelima observed variabel yang menjelaskan variabel laten kualitas layanan mempunyai nilai loading faktor $(\lambda)$ dan probabilitas seluruh indikator variabel masih di atas angka pembatas (cut off point) 0,40.

Hasil analisis menunjukkan nilai standardized loading faktor yang diperoleh mengkonfirmasikan bahwa keelima indikator variabel yang memiliki kontribusi tertinggi atas peningkatan variabel laten kualitas layanan adalah variabel manifes assurance dengan nilai loading factor sebesar 0,87.

Selanjutnya variabel manifes Responsiveness (daya tanggap) diperoleh nilai standardized loading factor sebesar 0,82 . Menyusul variabel manifes Reliability (keandalan) diperoleh nilai loading factor sebesar 0,76. Kemudian variabel manifes Empathy (empati) dengan nilai loading factor sebesar 0,72. Selanjutnya Tangibles (bukti terukur) diperoleh nilai standardized loading factor sebesar 0,58.

Hasil confirmatory factor analysis kelima indikator variabel laten kualitas layanan secara keseluruhan memiliki nilai loading factor $(\lambda)$ masih di atas angka pembatas (cut off point) 0,40 atau 40\%.

3) Hasil Estimasi Loading Faktor Variabel kepuasan (Y1)

Model pengukuran confirmatory factor untuk masing-masing observed variabel kepuasan disajikan pada Tabel berikut:

Tabel 9. Pengukuran confirmatory factor (loding faktor) variabel kepuasan

\begin{tabular}{lcc}
\hline Indikator & $\begin{array}{c}\text { Standardize Factor } \\
\text { Loading }\end{array}$ & Keterangan \\
\hline$(\mathrm{Y} 1.1)$ & 0,56 & \\
$(\mathrm{Y} 1.2)$ & 0,73 & Paling Besar \\
$(\mathrm{Y} 1.3)$ & 0,85 & \\
$(\mathrm{Y} 1.4)$ & 0,47 & Hasil \\
\hline \multicolumn{3}{c}{ Sumber : Data Primer di Olah 2016 } \\
analisis menunjukkan nilai standardized \\
loading faktor yang diperoleh \\
mengkonfirmasikan bahwa keempat \\
indikator variabel yang memiliki peranan \\
penting atau kontribusi terbesar terhadap \\
variabel laten kepuasan adalah variabel
\end{tabular}


manifes Kualitas pelayanan atau jasa dengan nilai loading factor sebesar 0,85.

Hasil confirmatory factor analysis keempat indikator variabel laten kepuasaan secara keseluruhan memiliki nilai loading factor $(\lambda)$ masih di atas angka pembatas (cut off point) 0,40 atau $40 \%$.

4) Hasil Estimasi Loading Faktor Variabel Loyalitas Mahasiswa (Y2)

Model pengukuran confirmatory factor untuk masing-masing observed variabel loyalitas disajikan pada Tabel berikut:

Tabel 10. Pengukuran confirmatory factor (loding faktor) variabel loyalitas mahasiswa

\begin{tabular}{lcc}
\hline Indikator & $\begin{array}{c}\text { Standardize Factor } \\
\text { Loading }\end{array}$ & Keterangan \\
\hline Y2.1) & 0,68 & Paling Besar \\
Y2.2) & 0,62 & \\
\hline
\end{tabular}

Sumber : Data Primer di Olah 2016

Hasil analisis data menunjukkan nilai standardized loading faktor yang diperoleh mengkonfirmasikan bahwa kedua indikator variabel yang memiliki peran tertinggi atau kontribusi terbesar dalam menjelaskan variabel laten loyalitas adalah variabel manifes Word of mouth dengan nilai loading factor sebesar 0,68.

Variabel manifes Complainin behavior berdasarkan hasil analisis menunjukkan bahwa perilaku komplain berperan dalam menjelaskan loyalitas mahasiswa di STIE Enam Enam Kendari. Hasil confirmatory factor analysis kedua indikator variabel laten loyalitas mahasiswa secara keseluruhan memiliki nilai loading factor $(\lambda)$ masih di atas angka pembatas (cut off point) 0,40 atau $40 \%$.

\section{F. Analisis Hasil Studi}

1) Uji Asumsi SEM

Hasil pengujian asumsi normalitas multivariate menunjukkan bahwa asumsi normalitas multivariate tidak terpenuhi karena diperoleh critical ratio (c.r) kurtosis 2,034 lebih besar daripada nilai kritis $\mathrm{Z}_{\text {tabel }}$ untuk $\alpha=5 \%$ yaitu 1,96 . Namun demikian, berdasarkan dalil limit pusat yang definisi secara bebasnya menyatakan ; bilamana sampel semakin besar (banyak berpendapat > 30) maka statistik yang diperoleh akan berdistribusi normal. Dengan demikian tidak diperlukan lagi asumsi normalitas data (Solimun : 2010 : 179). Pada penelitian ini besar sampel $(\mathrm{n}=120)$ dipandang sudah memenuhi dalil limit pusat, sehingga asumsi normalitas data tidak bersifat kritis dan dapat diabaikan. Hasil uji asumsi normalitas data dapat dilihat pada Tabel 11.

Tabel 11. Hasil uji normalitas data

\begin{tabular}{lrrrrrr}
\hline Variable & $\min$ & $\max$ & skew & c.r. & kurtosis & c.r. \\
\hline Y22 & 1,000 & 5,000 & $-2,212$ & $-9,892$ & 2,035 & 1,942 \\
Y21 & 1,000 & 5,000 &,- 670 & $-2,998$ &, 706 & 1,580 \\
Y11 & 1,000 & 5,000 & $-2,277$ & $-10,185$ & 1,012 & 1,493 \\
Y12 & 1,000 & 5,000 &,- 447 & $-2,001$ &,- 353 &,- 790 \\
Y13 & 1,000 & 5,000 &,- 582 & $-2,601$ &,- 392 &,- 877 \\
Y14 & 1,000 & 5,000 &,- 577 & $-2,579$ & 1,027 & 1,966 \\
X21 & 1,000 & 5,000 &,- 553 & $-2,474$ &,- 558 & $-1,248$ \\
X22 & 1,000 & 5,000 &,- 781 & $-3,493$ &, 716 & 1,601 \\
X23 & 1,000 & 5,000 &,- 464 & $-2,075$ &,- 096 &,- 215 \\
X24 & 1,000 & 5,000 &,- 710 & $-3,175$ & -570 & 1,275 \\
X25 & 1,000 & 5,000 &,- 487 & $-2,177$ &,- 190 &,- 426 \\
X11 & 1,000 & 5,000 &,- 491 & $-2,195$ &,- 607 & $-1,357$ \\
X12 & 1,000 & 5,000 &,- 275 & $-1,230$ &,- 934 & $-2,088$ \\
X13 & 1,000 & 5,000 &,- 603 & $-2,695$ &,- 143 &,- 321 \\
X14 & 1,000 & 5,000 &,- 037 &,- 167 &,- 224 &,- 501 \\
Multivariate & & & & & 2,569 & 2,034 \\
\hline
\end{tabular}


Sumber : Data Primer di Olah 2016

Uji outlier. Pengujian outliers dalam penelitian ini menggunakan kriteria Jarak Mahalanobis (Mahalanobis distance pada tingkat probabilitas lebih kecil dari $0,001=p<0,001)$. Jumlah indikator variabel dalam penelitian ini adalah 45 pertanyaan sehingga $\chi^{2}$ adalah $(21: 0,05)$ $=$ 69.956. Data yang mempunyai nilai mahalanobis distance lebih besar dari $\chi^{2}$ menunjukkan terjadi multivariate outliers. Hasil output pengolahan data dengan menggunakan software AMOS tidak terdapat nilai mahalanobis distance lebih besar dari nilai $\chi^{2}=64.797$. Nilai mahalanobis distance maksimum adalah
63,758 pada observasi atau sampel ke 1 dan nilai mahalanobis distance minimum adalah 7,861 pada observasi atau sampel ke 102. Dengan demikian data yang digunakan dalam penelitian ini tidak mengandung outliers secara multivariate sehingga data tersebut memenuhi persyaratan dalam model struktural.

Uji linearitas. Pengujian linearitas dalam penelitian ini menggunakan curva fit. Ringkasan analisis tersebut dapat dilihat pada tabel berikut ini.

Tabel 12. Ringkasan hasil pengujian linearitas antar variabel

\begin{tabular}{cccc}
\hline $\begin{array}{c}\text { Variabel } \\
\text { independen }\end{array}$ & Variabel dependen & $\begin{array}{c}\text { Nilai Sig. Untuk } \\
\text { Kriteria Linear }\end{array}$ & $\begin{array}{c}\text { Keterangan } \\
\text { Hubungan }\end{array}$ \\
\hline Pembelajaran & Kepuasan & 0,002 & Linear \\
Kualitas Layanan & Kepuasan & 0,000 & Linear \\
Kualitas Layanan & Loyalitas & 0,000 & Linear \\
Kepuasan & Loyalitas & 0,000 & Linear \\
\hline
\end{tabular}

Sumber : Data primer di olah 2016

Hasil analisis menunjukkan bahwa model linear yang dihasilkan signifikan $(0,000)$. Dengan demikian, maka data yang digunakan dalam penelitian ini memenuhi persyaratan linearitas data.

\section{2) Analisis Kelayakan Model Struktural}

Analisis kelayakan model structural (Good of- fit ) digunakan dalam penelitian ini untuk mengetahui kesesuaian data hasil observasi dengan model yang dibangun dan diestimasi dengan menggunakan analisis konfirmatori.
Hasil pemerikasaan Fit of model pada tabel di bawah menunjukkan bahwa dari tujuh kriteria, hanya AGFI yang menunjukkan model kurang baik dengan nilai sebesar 0,866. Ferdinand, (2006) nmenyatakan bahwa jika nilai 0,60 menunjukkan bahwa model ini diterima secara marginal. Sehingga secara keseluruhan hubungan antara variabel dapat dianalisis lebih lanjut karena model dianggap baik.

Tabel 13. Perbandingan indek kesesuaian model struktural dengan cut-off yang dipersyaratkan

\begin{tabular}{lccc}
\hline $\begin{array}{c}\text { Kriteria Kesesuaian } \\
\text { Model }\end{array}$ & $\begin{array}{c}\text { Indek Kesesuaian } \\
\text { Model }\end{array}$ & Cutt - off & Keterangan \\
\hline Chi-Squares & 95,893 & Kecil & Sudah fit \\
Probability & 0,218 & Non signifikan & Sudah fit \\
CFI & 0,932 & $\geq 0,90$ & Sudah fit \\
TLI & 0,917 & $\geq 0,90$ & Sudah fit \\
AGFI & 0,638 & $\geq 0,90$ & Marjinal \\
RMSEA & 0,076 & $0,05-0,08$ & Sudah fit \\
\hline
\end{tabular}

Sumber : Data Primer di Olah 2016 
3) Analisis Hubungan Struktural

Tabel 14. Standardized regression weight pengaruh langsung antar variabel laten.

\begin{tabular}{lclrrc}
\hline & Hubungan antar Variabel & $\begin{array}{r}\text { Koef. Jalur } \\
\text { Standar dize }\end{array}$ & p-value & Ket \\
\hline Kepuasan & $<---$ & Pembelajaran & 0,099 & $>0,05$ & No Sig. \\
Kepuasan & $<--$ & Kualitas Layanan & 0,755 & $<0,0001$ & Sig. \\
Loyalitas & $<---$ & Kualitas Layanan & 0,984 & $<0,0001$ & Sig. \\
Loyalitas & $<---$ & Kepuasan & 0,336 & 0,014 & Sig. \\
\hline
\end{tabular}

Sumber : Data Primer di Olah 2016

Berdasarkan rumusan masalah dan hipotesis penelitian yang telah dikemukakan sebelumnya maka pengaruh tidak langsung dalam penelitian ini adalah pengaruh kualitas layanan terhadap loyalitas melalui kepuasan nasabah. Untuk lebih jelasnya dapat dilihat pada tabel berikut :

Tabel 15. Pengaruh kualitas layanan terhadap loyalitas melalui kepuasan

\begin{tabular}{cccc}
\hline $\begin{array}{c}\text { Variabel } \\
\text { Independent }\end{array}$ & Variabel Mediasi & Variabel Dependet & $\begin{array}{c}\text { Pengaruh Tidak } \\
\text { Langsung }\end{array}$ \\
\hline Kualitas Layanan & Kepuasan & Loyalitas & 0,254 \\
\hline
\end{tabular}

G. Uji Hipotesis Penelitian

1) Pengujian Hipotesis 1 : Pembelajaran tidak berpengaruh signifikan terhadap kepuasan mahasiswa pada STIE Enam Enam Kendari.

Berdasarkan nilai Standardized Regression Weights pengaruh variabel pembelajaran terhadap kepuasan mahasiswa adalah sebesar 0,099 dengan probabilitas $>0,05$, nilai ini lebih besar daripada nilai level of significant $(\alpha)$ yang ditetapkan yaitu sebesar 0,05. Pembelajaran berpengaruh positif dan tidak signifikan terhadap kepuasan mahasiswa.

2) Pengujian Hipotesis 2 : Kualitas layanan berpengaruh signifikan terhadap kepuasan mahasiswa pada STIE Enam Enam Kendari.

Berdasarkan nilai Standardized Regression Weights pengaruh variabel kualitas layanan terhadap kepuasan mahasiswa adalah sebesar 0,755 dengan probabilitas <0,000 ( Tabel 5.4.3.1), nilai ini lebih kecil daripada nilai level of significant $(\alpha)$ yang ditetapkan yaitu sebesar 0,05 $(0,0001<0,05)$. Kualitas layanan berpengaruh positif dan signifikan terhadap kepuasan mahasiswa.
3) Pengujian Hipotesis 3 : Kepuasan berpengaruh signifikan terhadap loyalitas mahasiswa pada STIE Enam Enam Kendari.

Berdasarkan nilai Standardized Regression Weights pengaruh variabel kepuasan terhadap loyalitas adalah sebesar 0,336 dengan probabilitas 0,014 (Tabel 5.4.3.1), nilai ini lebih kecil daripada nilai level of significant $(\alpha)$ yang ditetapkan yaitu sebesar $0,05 \quad(0,014<0,05)$. Sehingga dapat disimpulkan kepuasan berpengaruh positif dan signifikan terhadap peningkatan loyalitas mahasiswa.

4) Pengujian Hipotesis 4 : Kualitas layanan berpengaruh signifikan terhadap loyalitas mahasiswa pada STIE Enam Enam Kendari.

Berdasarkan nilai Standardized Regression Weights pengaruh variabel kualitas layanan mahasiswa terhadap loyalitas mahasiswa adalah sebesar 0,984 dengan probabilitas $<0,000 \quad$ (Tabel 5.4.3.1), nilai ini lebih kecil daripada nilai level of significant $(\alpha)$ yang ditetapkan yaitu sebesar $0,05 \quad(0,0001<0,05)$. Kualitas layanan berpengaruh positif dan signifikan terhadap peningkatan loyalitas mahasiswa. 
5) Pengujian Hipotesis 5 : Kepuasan memediasi pengaruh kualitas layanan terhadap loyalitas mahasiswa pada STIE Enam Enam Kendari.

Hasil penelitian menunjukkan bahwa besarnya koefisien pengaruh langsung adalah 0,984 dan keofosien pengaruh tidak langsung 0,254. Untuk lebih jelasnya hubungan antara variabel dapat dilihat pada gambar berikut :

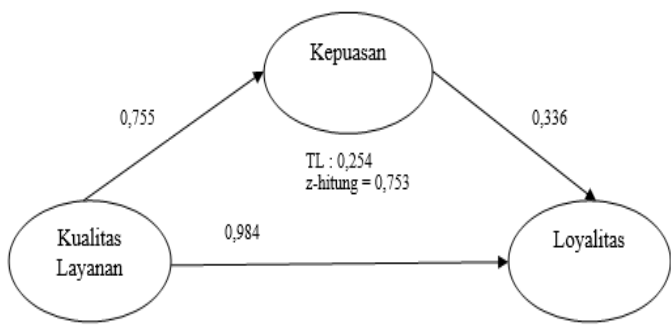

Gambar 2. Peran kepuasan dalam memediasi pengaruh kualitas layanan terhadap loyalitas

Untuk lebih memperjelas peran kepuasan dalam memediasi pengaruh kualitas layanan terhadap loyalitas di uji menggunakan rumus Sobel (Solimun, 2012) sebagai berikut :

Z-Hitung $=\frac{a \cdot b}{\sqrt{b^{2} \mathrm{Sa}^{2}+a^{2} \mathrm{Sb}^{2}}}$

Keterangan :

$\mathrm{ab}=$ Koefisien indirect effects

$\mathrm{a}=$ Koefisien direct effects kualitas layanan ke kepuasan

$\mathrm{b}=$ Koefisien direct effects kepuasan ke loyalitas

$\mathrm{Sa}=\quad$ Standard error dari koefisien a

$\mathrm{Sb}=$ Standard error dari koefisien $\mathrm{b}$

Berdasarkan rumus tersebut, maka pengujian pengaruh tidak langsung (mediasi) adalah sebagai berikut :

$$
\begin{aligned}
\text { Z-Hitung } & =\frac{0,253}{\sqrt{0.336^{2} 0,070^{2}+0.755^{2} 0,445^{2}}} \\
& =\frac{0,253}{\sqrt{0,112 \times 0,004+0.570 \times 0,198}} \\
& =\frac{0,253}{\sqrt{0,0005+0,1128}} \\
& =0,753
\end{aligned}
$$

Hasil perhitungan Sobel diperoleh z-hitung sebesar 0,753 jika dibandingkan dengan z-tabel maka di peroleh tingkat signifikansi statistik $0,753<1,96$ Pada taraf signifikansi statistik $\mathrm{z}$ (p-value) > 0,05 , berarti tidak terdapat indirect effects atau pengaruh tidak langsung variabel kualitas layanan terhadap loyalitas melalui kepuasan mahasiswa pad STIE Enam Enam Kendari.

4. Pembahasan

\section{A. Pembelajaran berpengaruh signifikan terhadap kepuasan mahasiswa pada STIE Enam Enam Kendari.}

Hasil pengujian hipotesis pertama mengkonfirmasikan bahwa pembelajaran tidak berpengaruh terhadap peningkatan kepuasan mahasiswa. Artinya perubahan pembelajaran mahasiswa tidak di ikuti dengan peningkatan kepuasan mahasiswa pada STIE Enam Enam Kendari. Hasil penelitian ini menunjukkan bahwa rencana pembelajaran, kualitas mengajar dosen, kualitas belajar serta penilaian dan pembelajaran tidak berdampak pada kepuasan mahasiswa STIE Enam Enam Kendari yang diukur dengan emosi, biaya, kualitas atas pelayanan jasa dan faktor pribadi.

Selain itu penyebab pembelajaran tidak berdampak pada kepuasan mahasiswa pada STIE Enam Enam Kendari adalah karena mayoritas dosen STIE Enam Enam Kendari masih tergolong mudah di bawah 35 Tahun sehingga masih perlu banyak pemberian microteaching agar dosen tersebut lebih mampu mentransfer ilmu pengetahun yang dimiliki dengan baik serta mampu menguasai ruang perkuliahan. Dengan adanya microteaching ini diharapkan dosen muda yang dimiliki oleh STIE Enam Enam Kendari mampu menguasai panggung dan dapat menghidupkan suasana pembelajaran agar tidak membosankan bagi mahasiswa.

Penyebab tidak siginifikanya pengaruh pembelajaran terhadap kepuasan mahasiswa tidak hanya disebabkan oleh 
faktor dosen saja tetapi juga disebabkan oleh faktor internal dan eksternal. Faktor yang mempengaruhi belajar dibedakan menjadi dua golongan, yaitu faktor intern dan faktor ekstern. Faktor intern adalah faktor yang ada dalam diri individu yang sedang belajar, sedangkan faktor ekstern adalah faktor yang berada di luar individu. Slameto. (2003:54) Yang termasuk faktor Intern antara lain: faktor faktor jasmaniah (faktor kesehatan dan cacat tubuh); faktor psikologis (intelligensi, perhatian, minat, bakat, motif, kematangan, dan kesiapan); dan faktor kelelahan (kelelahan jasmani dan rohani).

Sedangkan yang termasuk faktor ektern antara lain faktor keluarga (cara orang tua mendidik, relasi antar anggota keluarga, suasana rumah, keadaan ekonomi keluarga, pengertian orang tua, dan latar belakang kebudayaan); faktor sekolah (metode mengajar, kurikulum, relasi guru dan siswa, disiplin sekolah, alat pengajaran, standar pelajajaran di atas ukuran, keadaan gedung, metode mengajar, dan tugas rumah); dan faktor masyarakat (kegiatan siswa dalam masyarakat, mass media, teman bergaul, dan bentuk kehidupan masyarakat).

\section{B. Kualitas layanan berpengaruh signifikan terhadap kepuasan mahasiswa pada STIE Enam Enam Kendari.}

Hasil pengujian hipotesis kedua mengkonfirmasikan bahwa semakin baik kualitas layanan yang dirasakan mahasiswa akan meningkatkan kepuasan mahasiswa pada STIE Enam Enam Kendari. Artinya perubahan peningkatan kualitas layanan akan meningkatkan kepuasan mahasiswa pada STIE Enam Enam Kendari. Logika pemikiran yang mendasarinya adalah mahasiswa yang mengangap kualitas layanan yang diberikan baik maka akan meningkatkan kepuasan mahasiswa.

Hasil penelitian ini memperkuat teori dan beberapa hasil penelitian empirik yang menyimpulkan bahwa kualitas layanan berpengaruh positif dan signifikan terhadap kepuasan mahasiswa (Yap B W, et. al. 2012; I Nyoman et all, 2013). Hasil penelitian mereka menunjukkan bahwa peningkatan kualitas layanan akan menciptakan kepuasan yang lebih kuat terhadap suatu perguruan tinggi. Jadi mahasiswa akan puas apabila STIE Enam Enam Kendari dapat memberikan pelayanan dengan lebih baik.

Indikator selanjutnya yang memberi kontribusi terbesar dalam menjelaskan variabel kualitas layanan adalah Responsiveness (daya tanggap), yaitu kesediaan untuk membantu mahasiswa serta memberikan perhatian yang tepat. Keluhan dan kebutuhan pelayanan mahasiswa harus mampu direspon dengan cepat agar mahasiswa merasa benar-benar diperhatikan oleh tenaga pendidik dan tenaga kependidikan yang ada di STIE Enam Enam Kendari dengan demikian akan berdampak pada peningkatan kepuasan mahasiswa.

Selanjutnya indikator yang memberi kontribusi dalam merefleksikan variabel kualitas layanan adalah Reliability (keandalan). Keandalan dalam penelitian ini merujuk kepada kemampuan untuk memberikan layanan yang dijanjikan secara akurat dan handal. Selain itu Empathy (empati), mencakup kepedulian serta perhatian individual kepada para mahasiswa juga harus ditingkatkan dengan cara tenaga pendidik dan tenaga kependidikan harus jelih melihat setiap masalah yang dihadapi oleh mahasiswa dan harus mampu menyelesaikan masalah tersebut. strategi lain yang dapat dilakukan oleh pihak STIE Enam Enam Kendari adalah dengan terus meningkatkan suasana kekeluargaan yang terbangun antar mahasiswa, tenaga kependidikan dan tenaga pendidik sehingga diharpkan mahasiswa tidak sungkan untuk menyampaikan masalahnya kepada pihak STIE Enam Enam Kendari.

Aspek selanjutnya yang perlu diperhatikan adalah Tangibles (bukti terukur) yang mengambarkan fasilitas fisik, perlengkapan, dan tampilan dan personalia 
serta kehadiran para pengguna. Pihak STIE Enam Enam Kendari perlu terus meningkatkan sarana dan prasarana penunjang proses belajar mengajar seperti ruang kuliah yang nyaman, ketersediaan Infokus, layanan internet gratis di seluruh area kampus STIE Enam Enam Kendari serta ketersediaan buku-buku yang lebih baik di perpustakaan.

\section{Kepuasan berpengaruh signifikan terhadap loyalitas mahasiswa pada STIE Enam Enam Kendari.}

Hasil pengujian hipotesis ketiga mengkonfirmasikan bahwa semakin kepuasan mahasiwa maka loyalitas mahasiswa pada STIE Enam Enam Kendari akan meningkat. Artinya perubahan peningkatan kepuasan mahasiswa akan meningkatkan loyalitas mahasiswa pada STIE Enam Enam Kendari. Logika pemikiran yang mendasari adalah loyalitas mahasiswa pada STIE Enam Enam Kendari akan terwujud jika mahasiwa merasa merasa bangga menjadi mahasiswa STIE Enam Enam Kendari, biaya yang diberrlakukan sesuai dengan manfaat yang diperoleh, ketepatan dan kecepatan layanan dan kesesuai konsentrasi yang dibutuhkan mahasiswa.

Salah satu alasan kenapa terjadi perpindahan pelanggan dari satu perusahaan jasa ke perusahaan jasa yang lain adalah karena pelanggan tidak puas dengan kualitas layanan atau cara menghadapi masalah dari perusahaan jasa tersebut (Tronvoll 2007).

Berdasarkan hasil confirmatory factor analysis (CFA) diketahui bahwa indikator terbesar dalam merefleksikan kepuasan mahasiwa adalah Kualitas pelayanan atau jasa berdasarkan persepsi mahasiswa tentang ketepatan, kecepatan layanan tenaga kependidikan STIE Enam Enam Kendari. Dalam langkah ini, kecepatan dan ketepatan penanganan merupakan hal krusial. Ketidakpuasan dapat semakin besar apabila mahasiwa merasa kebutuhanya tidak dilayani dengan baik. Kondisi ini dapat menyebabkan mereka berprasangka buruk dan sakit hati sehingga berdampak pada penurunan loyalitas mahasiwa.

Selain itu aspek yang harus ditingkatkan dalam mewujudkan kepuasan nasabah berdasarkan prioritas adalah dengan melakukan beberapa hal sebagai berikut: biaya penyelenggaraan pendidikan harus sesuai dengan kualitas yang diberikan. Dengan membayar biaya penyelenggara pendidikan yang tinggi diharapkan sejalan dengan kualitas proses belajar mengajar yang diberikan. Perasaan bangga menjadi mahasiwa STIE Enam Enam Kendari juga perlu ditingkatkan dengan cara melibatkan mahasiswa dalam pengambilan keputusan akademik di STIE Enam Enam Kendari sehingga nantinya mahasiswa merasa bagian dari keluarga besar STIE Enam Enam Kendari.

\section{Kualitas layanan berpengaruh signifikan terhadap loyalitas mahasiswa pada STIE Enam Enam Kendari.}

Hasil pengujian hipotesis keempat mengkonfirmasikan bahwa semakin baik kualitas layanan maka loyalitas mahasiswa pada STIE Enam Enam Kendari akan meningkat. Artinya perubahan peningkatan kualitas layanan akan meningkatkan loyalitas mahasiswa pada STIE Enam Enam Kendari. Logika pemikiran yang mendasari adalah loyalitas mahasiswa pada STIE Enam Enam Kendari akan terwujud jika mahasiwa merasa fasilitas fisk yang diberikan memadai, memberikan layanan yang dijanjikan secara akurat dan tepat, kesediaan untuk membantu dan memberikan perhatian kepada mahasiswa, memberikan jamin yang baik dan karyawan peduli terhadap mahasiswa.

Hasil penelitian ini memperkuat teori dan beberapa hasil penelitian empirik yang menyimpulkan bahwa kualitas layanan berpengaruh positif dan signifikan terhadap loyalitas mahasiswa (Yap B W, et. al. 2012; I Nyoman et all, 2013; Noviana, 2007). Hasil penelitian mereka menunjukkan bahwa peningkatan kualitas 
layanan akan menciptakan loyalitas yang lebih kuat terhadap suatu perguruan tinggi. Jadi mahasiswa akan loyal apabila STIE Enam Enam Kendari dapat memberikan pelayanan dengan lebih baik.

\section{E. Peran kepuasan dalam memediasi pengaruh kualitas layanan terhadap kepuasan mahasiswa pada STIE Enam Enam Kendari.}

Hasil perhitungan Sobel diperoleh z-hitung sebesar 0,753 jika dibandingkan dengan z-tabel maka di peroleh tingkat signifikansi statistik $0,753<1,96$ Pada taraf signifikansi statistik $\mathrm{z}$ (p-value) > 0,05 , berarti tidak terdapat indirect effects atau pengaruh tidak langsung variabel kualitas layanan terhadap loyalitas melalui kepuasan mahasiswa pad STIE Enam Enam Kendari. Artinya bahwa kepuasan tidak berperan dalam memediasi pengaruh kualitas layanan terhadap loyalitas. Hal ini disebabkan karena kualitas layanan yang baik telah mampu meningkatkan loyalitas mahasiswa. Semakin baik kualitas layanan mahasiswa maka akan meningkatkan loyalitas mahasiswa. Dengan demikian hipotesis ke lima dalam penelitian ini ditolak.

Salah satu faktor yang mempengaruhi loyalitas pelanggan adalah kualitas pelayanan. Tjiptono (2007:58) menyatakan bahwa kualitas layanan apabila dikelola dengan tepat, berkontribusi positif terhadap terwujudnya loyalitas pelanggan. Kualitas memberikan nilai plus berupa motivasi khusus bagi para mahasiswa untuk menjalin ikatan relasi saling menguntungkan dalam jangka panjang dengan STIE Enam Enam Kendari.

Dalam mengambil kebijakan untuk meningkatkan loyalitas mahasiswa, manajemen STIE Enam Enam Kendari diharapkan memperhatikan kualitas pelayanan karena variabel ini berpengaruh secara langsung dalam meningkatkan loyalitas mahasiwa.

Berdasarkan hal tersebut maka Tangibles (bukti terukur), yang mengambarkan fasilitas fisik, perlengkapan, dan tampilan dan personalia serta kehadiran para pengguna hatus dimaksimalkan dengan baik. Reliability (keandalan), merujuk kepada kemampuan untuk memberikan layanan yang dijanjikan secara akurat dan handal harus terus ditingkatkan. Responsiveness (daya tanggap), yaitu kesediaan untuk membantu mahasiswa serta memberikan perhatian yang tepat kepada mahasiswa STIE Enam Enam Kendari yang membutuhkan bantuan. Assurance (Jaminan), merupakan karyawan yang sopan dan berpengetahuan luas yang memberikan rasa kepercayaan serta keyakinan kepada mahasiswa. Empathy (empati), mencakup kepedulian serta perhatian individual kepada para pengguna harus terus ditingkatkan.

\section{F. Kesimpulan}

Berdasarkan hasil penelitian, maka dapat dirumuskan beberapa kesimpulan sebagai berikut :

1. Pembelajaran berpengaruh positif dan tidak signifikan terhadap kepuasan, mahasiswa. Artinya bahwa pembelajaran tidak berdampak pada peningkatan kepuasan mahasiswa pada STIE Enam Enam Kendari.

2. Kualitas Layanan berpengaruh positif dan signifikan terhadap kepuasan mahasiswa. Semakin tinggi kualitas layanan yang diberikan kepada mahasiswa maka kepuasan mahasiswa pada STIE Enam Enam Kendari akan semakin tinggi.

3. Kepuasan berpengaruh positif dan signifikan terhadap loyalitas mahasiswa. Semakin tinggi kepuasan yang dirasakan mahasiswa maka loyalitasl mahasiswa pada STIE Enam Enam Kendari akan semakin tinggi.

4. Kualitas layanan berpengaruh positif dan signifikan terhadap loyalitas mahasiswa.

5. Kepuasan mahasiswa tidak memediasi pengaruh kualitas layanan terhadap loyalitas mahasiswa pada STIE Enam Enam Kendari. 